\title{
GROWTH, SURVIVAL, ANTIGENIC STABILITY, AND VIRULENCE OF LEPTOSPIRA INTERROGANS SERO- TYPE CANICOLA
}

\author{
H. C. Ellinghausen JR and G. M. Painter \\ National Animal Disease Center, North Central Region, Agricultural Research Service, \\ US Department of Agriculture, Ames, Iowa 50010, USA
}

VACCINES prepared against Leptospira interrogans serotypes canicola, icterohaemorrhagiae and pomona are widely used for the immunisation of domesticated animals in the USA, and vaccines against serotypes hardjo, grippotyphosa and szwajizak are at present under consideration. Both initial licensing and periodic potency testing of licensed leptospiral vaccines in the USA depend upon testing in hamsters.

Data related to the in-vitro preservation of leptospires has been published recently (Ellinghausen, 1973a and $b$ ). The present paper is concerned with serotype canicola and with matters of practical importance in relation to the propagation and testing of leptospiral vaccines. The scope of the experiments encompassed (1) investigation of the growth of virulent organisms in liquid, semisolid, and solid " polysorbate media", or in the same media after certain nutrient constituents had been either omitted or replaced by others, (2) assessment of the effect of simplified semisolid media other than " polysorbate media" on growth and on the preservation of virulence, (3) antigenic stability in different culture media, and (4) virulence after storage in culture media, suspending fluids and kidney homogenates, and virulence of cultures grown from single colonies.

\section{MATERIALS AND METHODS}

Media. The standard "polysorbate medium" contained polysorbate 80 (Tween 80 ), bovine albumin, ammonium chloride, thiamine, vitamin $\mathbf{B}_{12}$, sodium chloride, magnesium chloride, trace metals, and l-cystine, and it is referred to in this paper as P-80 medium and considered a complete medium. Media in which polysorbate 80 only was deleted and replaced by polysorbate 60,40 , or 20 are referred to respectively as P-60, P-40, and P-20 media. The media, already fully described by Ellinghausen (1973a and $b$ ), were used in the liquid, semisolid $(0.2 \%$ agar) and solid $(1 \%$ agar) forms.

Further modified media were produced by omitting certain constituents or replacing them by others. Eight such media shown in table I were employed to define better the multiple role that albumin plays. The media so listed in table I will hereafter be referred to as single or multiple deletion media. The "single deletion" media were complete in all respects except for the individual deletion of polysorbate 80 , ammonium chloride,

Received 28 Oct. 1974; revised version accepted 17 June 1975.

J. MED. MCROBIOL. - VOL. 9 (1976) 
thiamine, or vitamin $\mathbf{B}_{12}$. The " multiple deletion" media lacked both polysorbate 80 and ammonium chloride, and sometimes also one or both of thiamine and vitamin $\mathbf{B}_{12}$.

Asbestos-filtered P-80 medium was complete except for any substances removed as a result of the method of sterilisation.

"Simplified" semisolid media were made with a base of $0.005 \mathrm{M}$ phosphate $\left(\mathrm{KH}_{2} \mathrm{PO}_{4}\right.$ $87 \mathrm{mg}$ per 1 and $\mathrm{Na}_{2} \mathrm{HPO}_{4} 664 \mathrm{mg}$ per 1) partially solidified with $0.2 \%$ agar. This agarphosphate basal medium was used unsupplemented or supplemented with either (1) $1 \%$ bovine albumin, (2) $1 \%$ albumin and vitamin $\mathrm{B}_{12}$, (3) $1 \%$ albumin and thiamine, or (4) $1 \%$ albumin, vitamin $\mathrm{B}_{12}$ and thiamine. The simplified media lacked the $\mathrm{NH}_{4} \mathrm{Cl}, \mathrm{MgCl}_{2}, \mathrm{NaCl}$, trace metals, 1-cystine, and polysorbate present in complete $\mathbf{P}-80$ semisolid medium.

Leptospiral growth measurement and microscopic agglutination $(M A)$ test. These have already been described by Ellinghausen $(1973 a, b$, and $c)$.

Leptospira interrogans serotype canicola. Except where otherwise stated, the strain used was the virulent strain A-13 of the National Animal Disease Center culture collection (NADL A-13), maintained in P-80 semisolid medium at $23-25^{\circ} \mathrm{C}$ for 5 years.

Antigenic stability. After growth in various media, canicola was tested by the MA method with antisera against canicola (NADL A-13), canicola (Hond Utrecht IV), icterohaemorrhagiae (RGA), copenhageni (M-20), dakota (Grand River) and ballum (S-102). These strains were chosen because they represent leptospires that typically cross-agglutinate in various patterns with canicola. Serotype canicola antigen for the MA test, standardised as described by Ellinghausen (1973a), had a nephelometer reading of 25 and a Petroff-Hauser chamber count of $260 \times 10^{6}$ per ml.

Inocula for culture media and experimental hamsters. One hundred cultures of strain canicola (NADL A-13) in semisolid P-80 medium were stored at $23-25^{\circ} \mathrm{C}$ for future use. Two millilitres of preserved culture were gently inoculated drop by drop on to the surface of $10 \mathrm{ml}$ of fresh P-80 semisolid medium and incubated at $29^{\circ} \mathrm{C}$ until well grown. All such medium was tested before use to ensure that $10 \mathrm{ml}$ was capable of producing growth from an inoculum of two organisms. Two millilitres of the fresh culture were transferred to $10 \mathrm{ml}$ of liquid P-80 medium, vigorously shaken, and incubated for not more than $72 \mathrm{~h}$. To ensure the absence of more than a trace of agar, one further subculture was made in liquid P.80 medium and incubated until turbidity measurements indicated the required degree of growth.

Continuous subculture. One-ml volumes of liquid culture were transferred to $10-\mathrm{ml}$ volumes of parent medium and, after incubation, the process was repeated. All subcultures were incubated at $29^{\circ} \mathrm{C}$ for 14 days except those in complete P-80, P-60, P-40, and P-20 media, which were incubated for 7 days only.

Virulence tests in hamsters. Virulence titrations were made in weanling hamsters given intraperitoneally $1-\mathrm{ml}$ amounts of selected serial 10 -fold dilutions of bacterial suspension. The original suspension had a nephelometer reading of 25 and a Petroff-Hauser count of $260 \times 10^{6}$ cells per $\mathrm{ml}$. The doses selected were $26 \times 10^{6}, 2.6 \times 10^{3}, 2.6 \times 10^{2}, 26$, and 2 leptospires per animal and all dilutions were made in $1 \%$ bovine-serum-albumin diluent (BSAD) (Ellinghausen, 1973a).

Every experiment recorded in this paper was preceded by a confirmatory test of virulence; the test consisted of inoculating five weanling hamsters intraperitoneally with $2.6 \times 10^{3}$ leptospires and observing the characteristic mortality pattern together with the distribution of organisms in the brain, liver, kidney and blood at the time of death or slaughter.

\section{RESULTS}

\section{Growth, viability, and continuous subculture in 13 liquid media}

All the media contained $1 \%$ albumin. Inocula that supplied as few as two or three bacterial cells produced growth in P-80, P-60, P-40, and P-20 media and in $\mathrm{P}-80$ medium from which either polysorbate $80, \mathrm{NH}_{4} \mathrm{Cl}$, or 
TABLE I

Growth of Leptospira interrogans serotype canicola (strain NADL A-13) in 13 liquid media

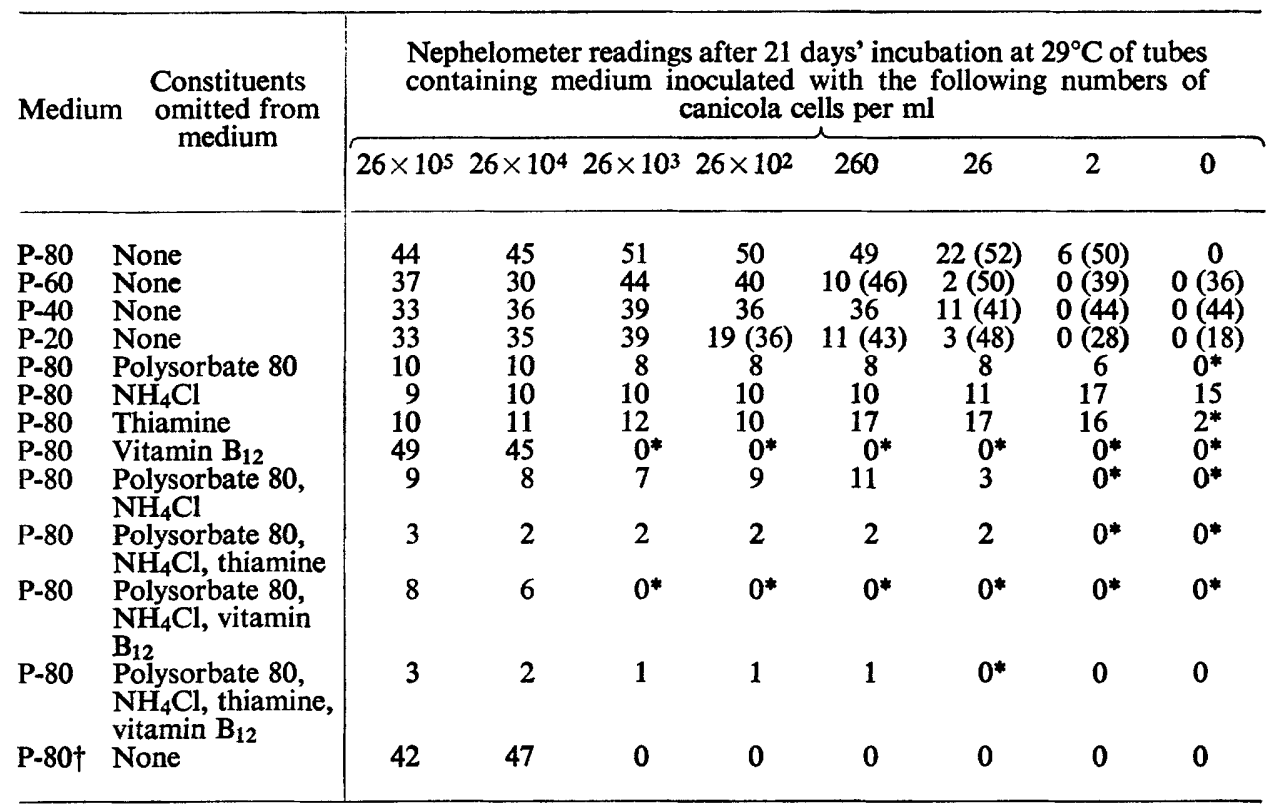

Nephelometer readings after $\mathbf{3 0}$ days' incubation are given in parentheses.

* After 21 days' incubation, presence of viable organisms shown by subculturing $1 \mathrm{ml}$ in P-80 semisolid medium. Zero readings without asterisk indicate that tubes were sterile after 21 days' incubation.

$\dagger$ Medium sterilised by a Seitz asbestos filter.

thiamine had been omitted (table I). The omission of vitamin $\mathrm{B}_{12}$ from P-80 medium greatly increased the size of the inoculum necessary to produce growth. The omission of the main carbon and nitrogen sources (polysorbate 80 and $\mathrm{NH}_{4} \mathrm{Cl}$ ) did not prevent the multiplication of organisms from small inocula, though the degree of growth was greatly reduced. The omission of the four constitutents polysorbate $80, \mathrm{NH}_{4} \mathrm{Cl}$, vitamin $\mathrm{B}_{12}$, and thiamine seriously impaired the growth of canicola. Complete P- 80 medium sterilised by means of a Seitz asbestos filter was capable of producing good growth, but only from large inocula. Table I also gives information on the survival of canicola in tubes that showed little or no turbidity after 21 days' incubation at $29^{\circ} \mathrm{C}$.

Continuous subculture of canicola was readily possible in P-80, P-60, P-40 and P-20 media, all cultures having a nephelometer reading of 55 (equivalent to approximately $5 \times 10^{8}$ cells per ml). Subculture in P-80 medium lacking polysorbate eventually failed, consecutive nephelometer readings being $9,7,6$, $3,2,3$, and 0 . $\mathrm{P}-80$ medium without $\mathrm{NH}_{4} \mathrm{Cl}$ maintained a constant though low level of growth, the nephelometer readings of seven subcultures being 13 , $11,11,11,12,12$, and 12 . Thiamine-deleted P-80 medium produced consecutive 
subcultures with readings of $58,38,6,1$, and 0 . Within the space of only three subcultures in vitamin $\mathrm{B}_{12}$-deleted medium, the reading had fallen to 0 . P-80 medium lacking both polysorbate 80 and $\mathrm{NH}_{4} \mathrm{Cl}$ produced a nephelometer reading of 10 throughout seven subcultures. Continuous subculture proved possible in medium sterilised by means of an asbestos filter if large inocula were used.

\section{Growth in semisolid polysorbate media}

Semisolid P-80, P-60, P-40, and P-20 media, and P-80 medium lacking $\mathrm{NH}_{4} \mathrm{Cl}$, all gave growth from an inoculum of only two organisms. A similar inoculum did not produce a well-defined zone of growth (Dinger's zone) in P-80 medium lacking polysorbate 80 , although darkfield microscopy demonstrated growth after 21 days' incubation at $29^{\circ} \mathrm{C}$. The deletion of thiamine from P-80 medium resulted in growth with a very indistinct Dinger's zone from an inoculum of two organisms, and the leptospires were all of reduced motility. Dinger's zones developed in P-80 medium lacking vitamin $\mathbf{B}_{12}$ from inocula of 26,000 leptospires or more, but not from 2600 .

\section{Growth in " simplified" semisolid media}

A characteristic Dinger's zone of growth was invariably absent, and darkfield examination was necessary to detect organisms, after incubation at $29^{\circ} \mathrm{C}$ for 21 days. Unsupplemented medium and medium supplemented with albumin alone or albumin and thiamine were positive on examination by darkfield microscopy when the inoculum was $2.6 \times 10^{4}$ cells, but not when it was $2.6 \times 10^{3}$ cells. Supplementation with both albumin and vitamin $B_{12}$, either alone or with the addition of thiamine, permitted growth from an inoculum of two cells.

\section{Growth on solid polysorbate media}

Table II shows that the various polysorbate media all produced colonies from small numbers of organisms with the exception of P-80 medium lacking vitamin $\mathbf{B}_{12}$.

\section{Antigenic stability during growth in various media}

Agglutinating suspensions of strain canicola (NADL A-13) were prepared from cultures grown in the first nine of the 13 liquid media already listed in table I. In the MA tests that were then carried out, each of the nine standardised suspensions (nephelometer reading of 25 ) demonstrated the full titre $\left(10^{5}\right)$ of a homologous antiserum.

After 10 serial subcultures in P-80, P-60, P-40, and P-20 media, canicola (NADL A-13) gave typical cross agglutination with antisera against strains canicola (Hond Utrecht IV), icterohaemorrhagiae (RGA), copenhageni (M-20), dakota (Grand River), and ballum (S-102). Cross-agglutination absorption studies were not performed. 
TABLE II

Colony formation by canicola (strain NADL A-13) on eight solid media

\begin{tabular}{|c|c|c|c|c|c|}
\hline \multirow{2}{*}{ Medium } & \multirow{2}{*}{$\begin{array}{l}\text { Component } \\
\text { omitted from } \\
\text { medium }\end{array}$} & \multicolumn{4}{|c|}{$\begin{array}{l}\text { Numbers of colonies that grew from } \\
\text { the following numbers of organisms }\end{array}$} \\
\hline & & $5.2 \times 10^{6}$ & 52 & 5 & 0 \\
\hline $\begin{array}{l}\text { P-80 } \\
\text { P-60 } \\
\text { P-40 } \\
\text { P-80 } \\
\text { P-80 } \\
\text { P-80 } \\
\text { P-80 }\end{array}$ & $\begin{array}{l}\text { None } \\
\text { None } \\
\text { None } \\
\text { Polysorbate } 80 \\
\mathrm{NH}_{4} \mathrm{Cl} \\
\text { Thiamine } \\
\text { Vitamin } \mathrm{B}_{12}\end{array}$ & $\begin{array}{l}C \\
C \\
C \\
C \\
C \\
C \\
C^{*}\end{array}$ & $\begin{array}{l}10 \\
\mathrm{C} \\
\mathrm{C} \\
\mathrm{C} \\
37 \\
35 \\
0\end{array}$ & $\begin{array}{l}1 \\
8 \\
1 \\
2 \\
1 \\
4 \\
0\end{array}$ & $\begin{array}{l}0 \\
0 \\
0 \\
1 \\
0 \\
0 \\
0\end{array}$ \\
\hline
\end{tabular}

Inocula in $0.2-\mathrm{ml}$ volumes were spread over the plates.

$\mathrm{C}=$ Confluent growth in the subsurface of the agar.

$*=$ Growth confluent, but so slight that it was barely detectable.

\section{Virulence tests in hamsters}

A typical virulence titration of strain canicola (NADL A-13) is shown in table III. Replicate experiments showed that the mean time to death was always predictable as long as the challenge cultures were prepared according to the method described under Materials and methods. Bacteriological examination of hamsters that died from the infection and survivors killed 7 days after the last occurrence of death in hamsters that received the smallest dose showed that kidney cultures provided a reliable indication of infection, but cultures from liver, lung, blood, and brain were also frequently positive. Positive tissue homogenates usually yielded growth when diluted 1 in $10^{5}$, and some were still positive when diluted 1 in $10^{8}$. Death was sometimes sudden with few premonitory signs, though there was often bleeding from the nostrils and the anus.

The kidneys were always greatly enlarged and engorged with blood. Petechial haemorrhages in the intestinal tract almost always occurred in animals that died. The livers were friable and the lungs were always covered with haemorrhages though to variable degrees.

\section{Survival in BSAD at $23-25^{\circ} \mathrm{C}$ of organisms derived from infected kidney}

Infected kidney tissue was obtained from hamsters that died or became moribund within 5 days of intraperitoneal inoculation with $2.6 \times 10^{8}$ canicola cells. A $10 \%$ tissue homogenate in BSAD was diluted decimally to extinction in the same medium, the final dilution being 1 in $10^{7}$. All tubes were kept at $23-25^{\circ} \mathrm{C}$ and subcultured periodically by transferring $1-\mathrm{ml}$ volumes to semisolid P-80 medium. By this method, viable organisms could be detected up to the 
TABLE III

Intraperitoneal virulence titration of canicola (strain NADL A-13) in weanling hamsters

\begin{tabular}{|c|c|c|c|c|c|c|c|c|}
\hline \multirow{2}{*}{$\begin{array}{l}\text { Number of } \\
\text { leptospires } \\
\text { injected }\end{array}$} & \multirow{2}{*}{$\begin{array}{l}\text { Number of } \\
\text { deaths in } \\
\text { groups of } \\
20 \text { hamsters }\end{array}$} & \multirow{2}{*}{$\begin{array}{l}\text { Mean time } \\
\text { (days) to } \\
\text { death }\end{array}$} & \multirow{2}{*}{$\begin{array}{c}\text { Number of } \\
\text { survivors* } \\
\text { found infected }\end{array}$} & \multicolumn{5}{|c|}{ Positive cultures from various tissues $\dagger$} \\
\hline & & & & Kidney & Liver & Lung & Brain & $\begin{array}{l}\text { Heart } \\
\text { blood }\end{array}$ \\
\hline $\begin{array}{l}26 \times 10^{6} \\
2,600 \\
260 \\
26 \\
2\end{array}$ & $\begin{array}{r}20 \\
19 \\
16 \\
13 \\
8\end{array}$ & $\begin{array}{r}4 \\
9 \\
10 \\
11 \\
13\end{array}$ & $\begin{array}{l}- \\
1 \\
4 \\
6 \\
2\end{array}$ & $\begin{array}{l}18 / 20 \\
18 / 19 \\
18 / 20 \\
18 / 20 \\
10 / 20\end{array}$ & $\begin{array}{r}12 / 15 \\
12 / 14 \\
18 / 20 \\
13 / 20 \\
4 / 14\end{array}$ & $\begin{array}{c}5 / 6 \\
11 / 13 \\
6 / 7 \\
2 / 2 \\
4 / 4\end{array}$ & $\begin{array}{c}10 / 10 \\
9 / 10 \\
8 / 8 \\
7 / 9 \\
4 / 6\end{array}$ & $\begin{array}{l}5 / 5 \\
6 / 6 \\
6 / 6 \\
3 / 3 \\
3 / 4\end{array}$ \\
\hline
\end{tabular}

* Survivors killed 7 days after the last occurrence of deaths in hamsters that received the smallest dose.

$\dagger$ Numerator $=$ number of positive cultures; denominator $=$ number of hamsters examined.

60th day, but by the 90th day recovery of organisms from the higher dilutions was irregular.

\section{Virulence of canicola after storage}

The infected kidney homogenate referred to above was used after 3 and 16 days' storage at $23-25^{\circ} \mathrm{C}$ to inoculate two tubes of semisolid $\mathrm{P}-80$ medium. Upon appearance of growth, subcultures were made in P-80 liquid medium. A second subculture in P-80 liquid medium was made to rid the culture of traces of agar. The culture originating from the kidney homogenate stored for 3 days was titrated intraperitoneally in graded 10 -fold doses ranging from $2.3 \times 10^{3}$ to two organisms in pairs of hamsters. The culture originating from the kidney homogenate stored for 16 days was used to inoculate pairs of hamsters with $2 \times 10^{7}, 2 \times 10^{3}, 2 \times 10^{2}, 20$ and 2 organisms. The mortality pattern corresponded closely with that shown in table III.

Organisms grown in artificial culture were suspended in BSAD and in phosphate buffer (PB) (Ellinghausen, 1973a) and kept for 7 days at $23-25^{\circ} \mathrm{C}$. Subcultures from the BSAD suspension and PB suspension were each titrated intraperitoneally in graded 10-fold doses ranging from approximately $1.6 \times 10^{7}$ to 1.6 organisms in pairs of hamsters. All died after intervals that could have been predicted from table III.

In a further experiment, the canicola strain was stored at $23-25^{\circ} \mathrm{C}$ in semisolid forms of the first eight media listed in table I and in each of the five " simplified media" described under Materials and methods. The number of organisms per $\mathrm{ml}$ inoculated into $10-\mathrm{ml}$ volumes of these 13 semisolid media at the beginning of the storage period was $26 \times 10^{6}$ cells, and 15 months later viable organisms were demonstrated in each of the 13 media by means of subculturing $2 \mathrm{ml}$ in parent medium or P-80 semisolid medium; Dinger's zones appeared in 6-10 days. Four hamsters were given liquid P-80 culture derived from each of the 13 stored cultures. The dose for each hamster was 260 cells, 
and there was no evidence that loss of virulence had occurred in the various semisolid storage media. Of the 52 hamsters given inoculations, 37 died in 10 to 11 days and canicola was invariably recovered from brain, kidney, and liver. Leptospires were usually isolated from one or more of these organs when the 15 survivors were killed and examined 14 days after infection.

\section{Virulence of cloned colonies}

Four, one, one, one, and five single colonies were picked from the following solid media, respectively: $\mathrm{P}-80, \mathrm{P}-60, \mathrm{P}-40, \mathrm{P}-80$ without $\mathrm{NH}_{4} \mathrm{Cl}$ and $\mathrm{P}-80$ without thiamine. Each colony was transferred to a semisolid form of the parent medium, then incubated at $29^{\circ} \mathrm{C}$ for 14 days and subsequently stored at $23-25^{\circ} \mathrm{C}$ for 10 months. Each stored culture was then subcultured, first in P-80 semisolid medium and then in P-80 liquid medium, and injected intraperitoneally into between one and four hamsters in doses of $2.6 \times 10^{7}$ and $2.6 \times 10^{3}$. Of 39 hamsters given inoculations, 32 died from leptospirosis within 10 days, suggesting that little or no loss of virulence had occurred.

\section{Discussion}

The fact that P-80, P-60, P-40, and P-20 media all gave satisfactory growth of strain canicola (NADL A-13) points to the vigorous growth capabilities of this strain. Some leptospires are much more demanding; for example, certain strains of serotype hardjo grow on P-80 medium but are incapable of growth on P-60, P-40, and P-20 medium (Ellinghausen, unpublished observation).

Continuous subculture was possible in P-80 medium from which either $\mathrm{NH}_{4} \mathrm{Cl}$ or polysorbate 80 was deleted, provided that both thiamine and vitamin $B_{12}$ were present, and it is felt that the importance of the albumin content of the medium cannot be overstressed. Even in simplified semisolid medium supplemented with albumin, thiamine and vitamin $B_{12}$, growth occurred; solid medium demonstrated more adequately the importance of added vitamin $B_{12}$. The vaccine-testing laboratory of the US Department of Agriculture maintains its hamster-virulent challenge strains by continuous passage through hamsters of homogenised liver tissue (Nervig, 1975, personal communication). This might explain why cell replication of canicola in vitro is so drastically impaired by a lack of vitamin $B_{12}$. Bovine albumin can be obtained in a state of purity (Ellinghausen, 1968) sufficient for the demonstration of the vitamin $\mathrm{B}_{12}$ requirement of leptospires, but although the thiamine in $\mathrm{P}-80$ medium can be shown to be required for maximal growth, the amount of this vitamin in various batches of bovine albumin sometimes makes it almost impossible to demonstrate an absolute requirement. If leptospires can be grown in a medium containing only albumin, vitamin $B_{12}$ and thiamine and found to be fully immunogenic, the importance of albumin will be even more conclusively proved.

We need to understand what constitutes the endogenous nutrient stores of leptospires and how such stores are related to survival and possibly virulence. 
The hardy nature of canicola was seen by its survival in diluted kidney homogenate, unsupplemented simplified medium and vitamin $B_{12}$-deleted medium. Growth in organ culture might be worthy of study. Miller, Miller and White (1966) have shown that growth of leptospires occurs in the presence of mammalian cells produced by tissue culture.

Further work is needed on growth of leptospires on solid agar, particularly with strains that are known to fluctuate in virulence in the laboratory. The uniformity of leptospiral colonial morphology offers no prospect of assistance in differentiating virulent from avirulent progeny. When strain canicola (NADL A-13) was studied, the overwhelming proportion of the cell population appeared highly virulent. Similar studies with leptospires that produce kidney infection but not death might be rewarding. Studies will also be required with different media to see if specific nutrients encourage a more rapid death rate of genetically virulent organisms than of genetically avirulent organisms.

How long cells can remain virulent without progressive growth is probably a function of endogenous stores. Ellinghausen (1973a) has described the maintenance of virulence of a strain of serotype pomona during prolonged storage in BSAD. Refined studies of such cells are needed to see if their chemical composition would shed some light on the problem. The preservative activity of BSAD may be related to some of the micronutrients reported in bovine serum albumin by Hanson and Ballard (1968) and Ellinghausen (1968).

Wilson and Foster (1971) have described limited proteolysis of bovine albumin by an enzyme present in commercial albumin preparations. This should be taken into account in view of the growth of leptospires that can be achieved in media from which ammonium chloride and polysorbate 80 have been omitted.

As Pearce and Lowrie (1972) have stated, we need a better understanding of the factors that control bacterial multiplication in vivo, and those that control host specificity. Simultaneous studies of host and infective agent are thus required.

\section{SUMMARY}

Leptospira interrogans serotype canicola (strain NADL A-13) grew from inocula as small as two cells in liquid polysorbate 80 medium (P-80 medium), in P-60, P-40 and P-20 media, and in P-80 medium from which polysorbate, $\mathrm{NH}_{4} \mathrm{Cl}$ or thiamine had been omitted. It grew well initially in vitamin $\mathbf{B}_{12^{-}}$ deleted P-80 medium, but only with inocula as large as $26 \times 10^{4}$ cells per ml.

P-80 medium lacking both polysorbate and $\mathrm{NH}_{4} \mathrm{Cl}$ supported light growth from small inocula, but the omission of thiamine and vitamin $\mathbf{B}_{12}$ in addition seriously affected the properties of the medium. Where readily detectable growth did not develop in liquid nutrient-deleted medium, viable organisms could often be demonstrated indirectly by subculture to semisolid medium, and their occurrence was influenced by the presence of albumin, thiamine, and vitamin $\mathrm{B}_{12}$.

Growth on semisolid media was comparable with that in liquid media 
of similar composition. The absence of polysorbate 80 , thiamine, or vitamin $\mathrm{B}_{12}$ prevented the appearance of Dinger's zones of growth from small inocula.

Antigenic composition as measured by microscopic agglutination tests with homologous and heterologous antisera was not appreciably affected by repeated subculturing in various complete and incomplete media.

Homogenates of infected-hamster-kidney tissue in bovine serum-albumin diluent still contained viable organisms after 60 days' storage at $23-25^{\circ} \mathrm{C}$. Organisms derived from this material after 3 and 16 days' storage showed no loss of virulence. Organisms grown in artificial culture showed no loss of virulence after storage in bovine albumin diluent or phosphate buffer for 7 days at $23-25^{\circ} \mathrm{C}$.

Cultures of the organism survived without loss of virulence for 15 months in 13 semisolid media of differing complexity. Single colonies derived from five different solid media were grown in semisolid forms of the parent media and stored at $23-25^{\circ} \mathrm{C}$ for 10 months without loss of virulence.

\section{REFERENCES}

Ellinghausen, H. C., JR 1968. Culture and biochemical characteristics of a leptospire from frog kidney. Wildlife Dis. 4, 41.

ELLINGHAUSEN, H. C., JR 1973a. Growth temperatures, virulence, survival, and nutrition of leptospires. J. med. Microbiol., 6, 487.

ELLINGHAUSEN, H. C., JR $1973 b$. Virulence, nutrition and antigenicity of Leptospira interrogans serotype pomona in supplemented and nutrient deleted bovine albumin medium. Annls Microbiol., 124B, 477.

Ellinghausen, H. C., JR 1973c. Death and lysis of leptospirae when cultured in asbestosfiltered growth media. Appl. Microbiol., 26, 959.

HANSON, R. W. AND Ballard, F. J. 1968. Citrate, pyruvate, and lactate contaminants of commercial serum albumin. J. Lipid. Res., 9, 667.

Miller, R. E., Miller, N. G. AND WhITE, R. J. 1966. Growth of Leptospira pomona and its effect on various tissue culture systems. J. Bact., 92, 502.

PeArCE, J. H. AND Lowrie, D. B. 1972. Tissue and host specificity in bacterial infection. In Microbial pathogenicity in man and animals, 22nd Symp. Soc. Gen. Microbiol., edited by H. Smith and J. H. Pearce, London, p. 193.

Wilson, W. D. AND Foster, J. F. 1971. Conformation-dependent limited proteolysis of bovine plasma albumin by an enzyme present in commercial albumin preparations. Biochemistry, N.Y., 10, 1772. 